\title{
Simulation of selected management strategies on Canterbury sheep farms ${ }^{1}$
}

J.D. FINLAYSON, O.J. CACHO and A.C. BYWATER Farm Management Department, Lincoln University

\begin{abstract}
A simulation model was used to investigate the effects of various combinations of stocking rate, drafting weight and lambing season on a hypothetical dryland farm in Canterbury. A selection of physical results is presented and financial implications of alternative management strategies are briefly discussed. Stocking rate and lambing time had considerable effects on animal performance, with minor effects from drafting weight. Gross margins were considerably affected by stocking rate; the highest return was obtained with conventional lambing at 15 su per ha and drafting lambs at $30 \mathrm{~kg}$ empty body weight.
\end{abstract}

Keywords model, management strategy, sheep farm

\section{Introduction}

A simulation model for evaluating alternative management strategies on sheep farms has been developed. Full details of the biological, managerial and economic components of the model and its evaluation are given by Finlayson (1989). This paper briefly summarises the model and illustrates how it might be used to analyse a selection of management strategies for a hypothetical dryland Canterbury property.

\section{Model overview}

The model consists of a series of dynamic lists of records which store information on the characteristics and current status of pastures and -animals on the property. The central structures within the model are paddocks, pasture areas, mobs and animals (Figure 1). These represent the physical entity of the farm. Management aspects are represented through an event list which controls the operation of the model with respect to animal husbandry, grazing management, and animal

1 This research was supported in part by a grant from the AGMARDT trust. O.J. Cacho is a UGC Post-Doctoral fellow.

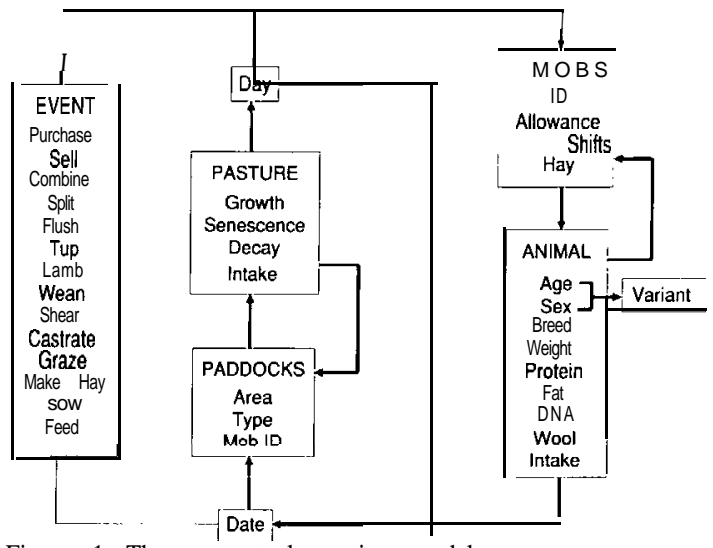

Figure 1 The conceptual grazing model.

purchases and sales. Paddock and mob records provide logical management units within the model and act as the link between animals and pastures. Events cause a reorganisation of these records, the relationships between them or the state of the animals or pastures.

\section{Paddocks and pasture areas}

Paddock records contain information on the area, type of paddock, and a reference to the grazing mob (if any). A permanent list of paddocks is estäblished at the start of the model run and 4 temporary lists indicate which paddocks are being grazed, used for hay, used for a feed crop, or available for future grazing. Paddocks may be combined together or subdivided into one or more pasture areas. This allows representation of grazing strategies from mob stocking to strip grazing.

Pasture records contain information on leaf and stem growth, senescence and decay. The current date determines whether the pasture is vegetative or reproductive, and affects rates of growth. Daily pasture growth (leaf and stem) is calculated from seasonal growth curves and depends on existing herbage mass (Figure 2). Pasture growth is assumed to be a logistic function of ceiling leaf mass (Christian et al. 1978). Growth rate values for the analysis reported here were derived from data recorded by Rickard \& McBride (1986).

\section{Mobs and animals}

Each mob is associated with a paddock and is composed of one or more animal groups that are 


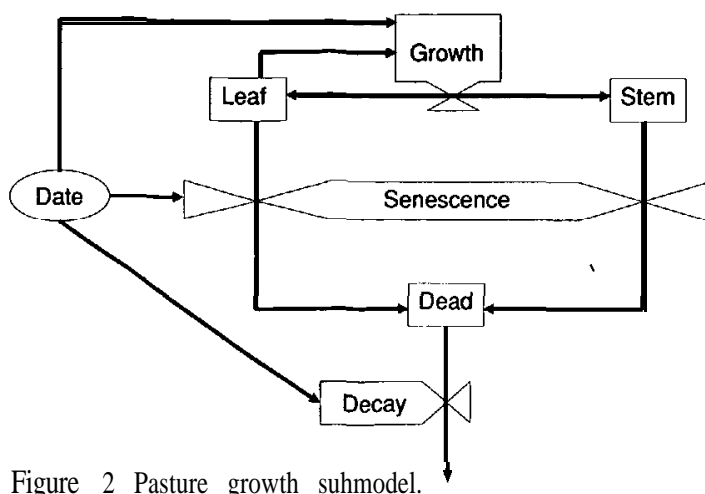

managed together. Grazing rules specified in mob records define target pasture allowance at the time the mob is shifted, time between shifts and the amount of hay received. Grazing rules can be changed at any time through the event list. When a mob is to be shifted, the model inspects the list of paddocks available for grazing, and decides where to move the mob according to allowance and pasture availability.

Each animal record represents a group of animals assumed to conform to a normal distribution. All animals within a group belong to the same sex, age, breed and reproductive status. Animal records contain information on body weight, protein, fat, DNA, wool, energy requirements and food intake; they also contain a variant part representing animals in different reproductive states. Pregnant ewe records contain information on conception date, sire breed and number of fetuses. When lambing occurs, reproductive status is changed to lactating ewe and the record includes a reference to the lamb record(s) and information on the amount of milk available in the ewe's udder.

A variety of different approaches has been used to model food intake by grazing animals (Elsen et al. 1988). In this model pasture intake is determined by the interplay of metabolic energy needs, the physical capacity of the rumen and the availability of different pasture components. Functions to estimate metabolic requirements were based on work by Bywater (1984), Oltjen $\boldsymbol{e t}$ al. (1986) and St-Pierre \& Bywater (1987). Physical limits to intake were based on information from Bines (1971), Grovum (1979) and Kahn \& Spedding (1984).

The animal submodel accounts for the nutritional and physiological status of each group of animals (Figure 3). Partition of energy between competing processes is hierarchical, with maintenance and pregnancy requirements being satisfied first. Demands for lactation, wool growth and lean body gain are determined on the basis of season and/or physiological state as described below and are then adjusted for current nutritional state. Any discrepancy between energy intake and use in these processes is reflected in fat gain or loss.
Demand for gains in lean body mass is based on models developed by St-Pierre \& Bywater (1987) and Oltjen $\boldsymbol{e} t$ al. (1986). Wool growth is determined by breed and body weight of the animal modified by a sine function to account for seasonal effects. Wool growth functions are based on work by Bigham et al. (1978), Nagorcka (1979) and White et al. (1983).

Requirements for lactation are based on a Wood's curve (Wood 1967) adjusted to reflect the number of lambs reared. Reproductive functions are based on McCall (1984). Conception rates of mature cycling animals and the probability of multiple ovulations depend on the time of year when ewes are tupped, ewe liveweight, and the rate of liveweight change in the period before joining (Rattray et al. 1981) Energy requirements for pregnancy depend on ewe liveweight, the weight and number of fetuses and days since conception.

Events

The concept of using an event list is similar to that of Christian et al. (1978). The event list is read from an input file at the start of a run and new events are added by the model at run time. Event records are ordered by date and instruct the model to perform a given task. Information required by different events varies according to their nature; thus variant records are intensively used in this context. Each simulated day the model inspects the event list and if an event is found, the appropriate information is obtained from the record and acted upon. Actions prompted by the event list include movement of animal groups between mobs, movement of mobs between paddocks, closure of paddocks for feed crops, animal shearing and selling, etc. (see Figure 1).

\section{Method of analysis}

To illustrate how the model might be used to investigate the effects of various management strategies a $4 \times 5 \times 3$ factorial comparison was conducted for a hypothetical dryland farm in Canterbury. Factors analysed were:

1. Stocking rate: $9,12,15$ and 18 animals/ha.

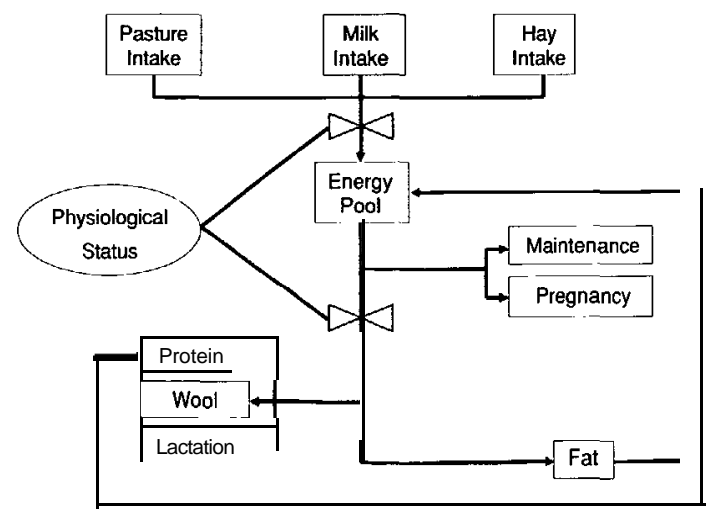

Figure 3 Animal growth submodel. 
DRAFTING WEIGHT $26 \mathrm{~kg}$ DRAFTING WEIGHT, $34 \mathrm{~kg}$ DRAFTING WEIGHT. $42 \mathrm{~kg}$

Empty Body Weight $(\mathbf{k g})$
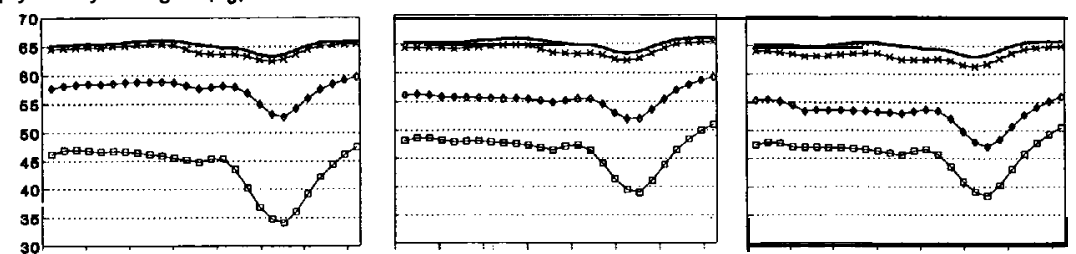

Energy Intake (MJME/day)
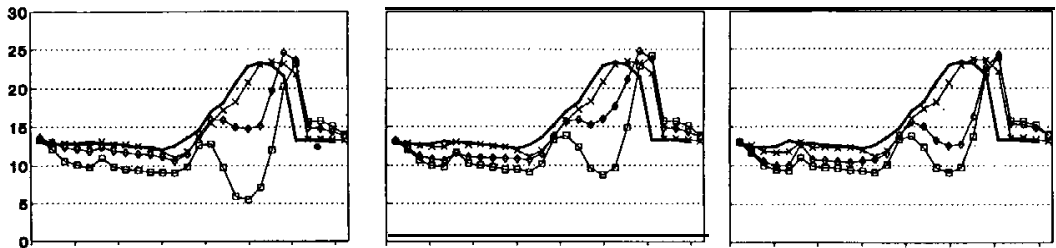

Pasture Dry Matter (100 kg/ha)

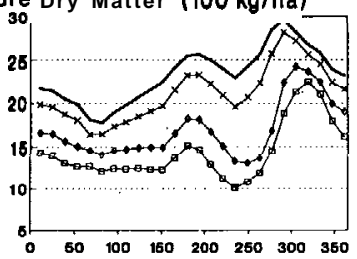

Day

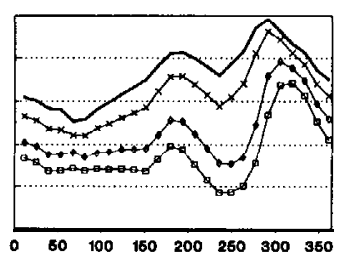

Day

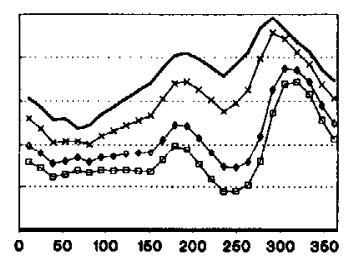

Day

Stocking Rate ${ }_{*}^{12} \quad 15 \quad 18$

Figure 4 Selected physical results. (Mid-August lambing; day 1 is 1 January).

2. Lamb drafting weight: $26,30,34,38$ and $42 \mathrm{~kg}$ empty body weight (EBW).

3. Time of lambing: Conventional mid-August lambing; all S-year ewes lambed in May (15\% autumn lambing); a proportion of mixed age ewes plus all 5-year ewes lambed in May (30\% autumn lambing).

Each combination of management parameters was simulated over a 4-year period, the first year's results were discarded and results from the remaining years were averaged.

The hypothetical farm has a self-replacing Corriedale flock on 100 ha subdivided into 20 equalsize paddocks. Farm income is derived from the sale of wool, hay, live animals and animals for slaughter. Lambs are sorted into meat grades according to carcass weight and GR. Equations estimated by Kirton et al. (1985) were used to calculate GR from the body fat values predicted by the model.

Each run of the model generates a wide range of physical and financial output. Physical data are output at time intervals determined by the user and include the rate of growth and cover of all pasture components; various measures of pasture intake, bodyweight and composition of each class of stock; various measures of performance; lambs sold, average sale weight and grade by drafting date; and the weight of wool produced and sold. Financial data are in the form of a gross margin calculation which includes all costs and returns that vary between runs in any given analysis, but excludes items which are either fixed costs (e.g. rates, mortgage payments, etc.) or those which will not vary with the management alternatives being considered. Costs included in the current analysis are those associated with animal health expenditures, shearing, cartage and feed plus all commissions and sale charges.

Output from each run is stored in a data file and then is transferred to a spreadsheet for ease of manipulation and presentation. Output from a number of runs can be combined in the spreadsheet to allow comparisons of different strategies and to identify any trends associated with particular management parameters.

\section{Results}

There are only small differences between the lowest, highest and middle drafting weights, with a tendency for pasture cover to be lower during summer, autumn and early winter as lambs are kept on longer to reach higher weights (Figure 4). Differences between the four stocking rates are much more 
Net Revenue from Wool Sales $(\$ 1000)$

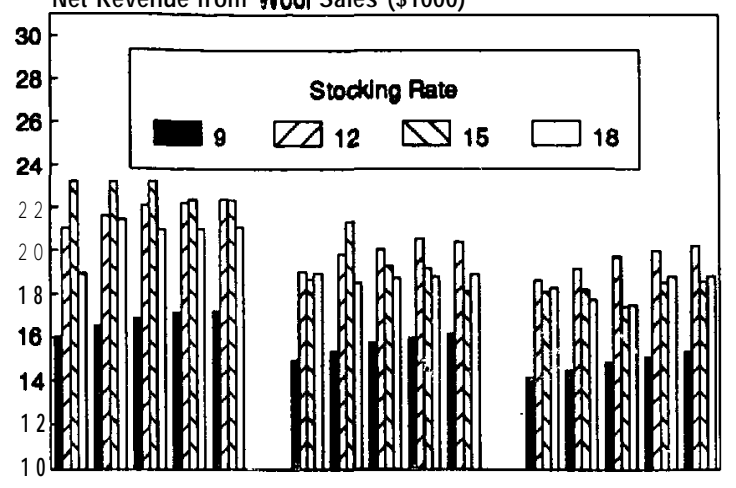

Net Revenue from Meat Salos (\$ IWO)

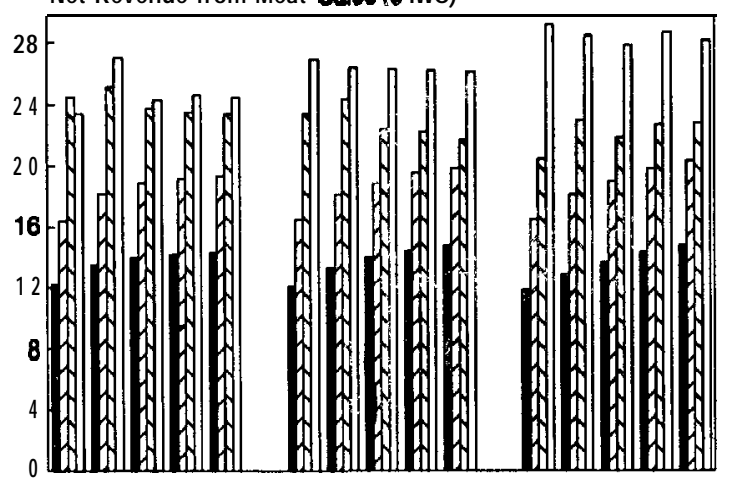

45 Gross Margln (\$1000)

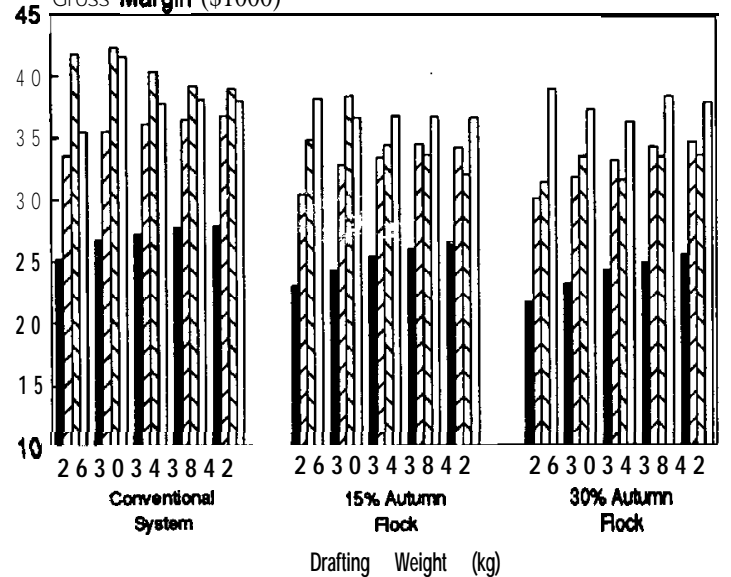

Figure 5 Financial results.

marked. Pasture cover and ewe energy intake and bodyweight all decrease with increased stocking rate. Peak energy intake in spring is delayed at the higher stocking rates, which reflects the fact that increased stocking rate delays the increase in pasture growth rates in spring (not shown in Figure 4).

Although not shown here, these production patterns are similar when 15 or $36 \%$ of the flock are lambed in autumn. For each drafting weight and stocking rate, the effect of early lambing is to decrease pasture cover during late winter and early spring with no change or an increase in pasture cover in late summer. These differences are reflected in energy intakes and body weights.

In line with the production patterns described above, animal performance and performance per ha are generally more sensitive to changes in lambing time and stocking rate than they are to changes in drafting weight. Wool production per animal declines consistently with stocking rate and with earlier lambing. With conventional lambing, production per ha increases with stocking rate up to 15 su per ha but declines at 18 su per ha, which is reflected in the revenue received from wool (Figure 5 ). With part of the flock lambing early, the pattern is similar but rather more erratic when compared over different lamb drafting weights. Peak wool production per ha tends to occur at lower stocking rates as lamb drafting weight is increased and a higher proportion of the flock are lambed early.

Lambing percentage is severely depressed by lambing part of the flock in May, as might be expected. However, lambing percentage at all lambing times and for all lamb drafting weights is projected to be higher at 15 and 18 super ha than at 9 or 12 su per ha. This is because of the patterns of bodyweight change illustrated in Figure 4; at the two higher stocking rates, ewes lose weight after lambing and during lactation and are still gaining weight before and during tupping. At the lower stocking rates, ewes, while heavier throughout, do not lose as much weight during lactation and are only maintaining weight during tupping. The additional flushing effect at the higher stocking rates increases lambing percentage.

Differences in lambing percentages are compensated for by higher average lamb prices for the early lambing flocks. Net revenues from lamb sales (Figure 5) are actually slightly higher for the early lambing systems. Lambing rates are higher for the two higher stocking rates as discussed above, but lambs tend to be drafted earlier and at heavier average weights, with the two lower stocking rates giving similar meat production per su at each drafting weight. As drafting weight increases meat production per su increases slightly. The overall effect is that meat production per ha and total revenue increase with stocking rate.

When wool and meat revenues are combined with expenses, total gross margins (Figure 5) are slightly higher for the conventional lambing times than for any of the early lambing alternatives. Despite the higher revenue from lamb sales, earlier lambing options earn less from wool and have higher animal health (including breeding) and feed costs. The highest gross margin overall is for conventional lambing at 15 su per ha and drafting at $30 \mathrm{~kg}$ empty body weight, which would be quite typical of many Canterbury sheep properties. 
For all three lambing times and at all drafting weights, gross margins at 9 su per ha are significantly lower than for the other three stocking rates. Where lamb drafting weights are low, gross margin is quite sensitive to stocking rate at 12,15 and 18 su per ha, but as the drafting weight is increased - which has the effect of increasing the overall feed demand there is not a lot of difference in gross margin between the three higher stocking rates. Gross margins at stocking rates of 15 and 18 su per ha decline as drafting weight goes up, indicating that higher drafting weights effectively increase feed demand beyond the optimum with highly stocked systems. In contrast, gross margins at 12 su per ha increase slightly as drafting weight goes up, suggesting that the additional feed demand of the lambs is not having a detrimental effect.

Overall there are a number of combinations of management policies which have gross margins within 10\% of the highest gross margin. The current analysis has used data for what might be described as typical or average seasons, both with respect to pasture production and prices. It is possible that including a greater range of seasonal conditions (both production and price) would result in a clearer differentiation between systems with respect to the riskiness as well as the level of their financial returns. This is an issue which it is hoped the model will be used to resolve in the future.

\section{REFERENCES}

Bigham, M.L.; Sumner, R.M.W.; Elliot, K.H. 1978. Seasonal wool production of Romney, Coopworth, Perendale, Cheviot and Corriedale wethers. NZ journal of agricultural research 21: 377-382.

Bines, J.A. 1971. Metabolic and physical control of food intake in ruminants: Proceedings of the Nutrition Society 30: 116-122.

Bywater, A.C. 1984. A generalised model of feed intake and digestion in lactating cows. Agricultural systems 13: $167-186$.

Christian, K.R.; Free, M.; Donnelly, J.R.; Davidson, J.L. Armstrong, J.S. 1978. Simulation of grazing systems. Simulation Monographs. Pudoc, Wageningen $115 \mathrm{pp}$.

Elsen, J.M.; Wallach, D.; Charpentau, J.L. 1988. The calculation of herbage intake of grazing sheep: a detailed comparison between models. Agricultural systems 26: 123-160.
Finlayson, J.D. 1989. A simulation study of out of season lamb production. MAgrSc Thesis, Lincoln College,

Grovum, W.L. 1979. Factors affecting the voluntary intake of food by sheep. 2. The role of distention and tactile input from the compartments of the stomach. British journal of nutrition 42: 425-436.

Kahn, H.E.; Spedding, C.R. W. 1984. A dynamic model for the simulation of cattle herd production systems: 2-An investigation of various factors influencing the voluntary intake of dry matter and the use of the model in their validation. Agricultural systems 13: 63-82.

Kirton, A.H.; Duganzich, D.M.; Feist, C.L.; Bennet, G.L.; Woods, E.G. 1985. Prediction of lamb carcass composition from GR and carcass weight. Proceedings of the NZ Society of Animal Production 45: 63-65.

McCall, D.G. 1984. A systems approach to research planning for North Island hill country. PhD Thesis, Massey University.

Nagorcka, B.N. 1979. The effect of photoperiod on wool growth. In Black, J.L.; Reis, P.J. (Eds). Physiological and environmental limitations to wool growth. University of New England Publishing Unit, Armidale, pp. 127-138.

Oltjen, J.W.; Bywater, A.C.; Baldwin, R.L.; Garret, W.N. 1986. Development of a dynamic model of beef cattle growth and composition. Journal of animal science 62: 86-97.

Rattray, P.V.; Jagusch, K.T.; Smith, J.F.; Winn, J.W.; MacLean, K.S. 1981. Effects of genotype, pasture type and feeding level on ovulation responses in ewes. Proceedings of the NZ Society of Animal Production 41: $174-182$.

Rickard, D.S.; McBride, S.D. 1986. Irrigated and nonirrigated pasture production at Winchmore, 1960 to 1985. Technical report 21, Winchmore Irrigation Research Station, 75 pp.

St-Pierre, N.R.; Bywater, A.C. 1987. Development of a dynamic model of sheep growth and composition. Ministry of Agriculture and Fisheries Research Paper 2787. Ruakura, Hamilton: 30 pp.

White, D.H.; Bowman, P.J.; Morley, F.H.W.; McManus, W.R.; Filan, S.J. 1983. A simulation model of a breeding ewe flock. Agricultural systems IO: 149. 189.

Wood, P.D.P. 1967. Algebraic model of the lactation curve in cattle. Nature 216: 164-165. 